\title{
The Analysis of Yunnan Ethnic Costume Elements in Children's Stage Costume-Taking Miao, Yi, Dai as an Example
}

\author{
Shengnan Chen ${ }^{1} \&$ Yanmei $\mathrm{Li}^{1}$ \\ ${ }^{1}$ Fashion Design and Engineering, Shanghai University of Engineering Science, shanghai, China \\ Correspondence: Yanmei Li, Associate Professor, College of fashion, Shanghai University of Engineering Science, \\ China. E-mail: 13918224965@126.com
}

Received: April 17, 2015

Accepted: April 22, 2015

Online Published: April 25, 2015

doi:10.5430/jbar.v4n1p24

URL: http://dx.doi.org/10.5430/jbar.v4n1p24

\begin{abstract}
Yunnan national traditional costume is the quintessence of Chinese culture, it is the crystallization of the wisdom of thousands of years of history in the creation of the working people during the production and practice, which embodies the Chinese nation and the spirit of the feelings. In the globalization of today, according to the Yunnan national tradition clothing's own law of development, combined with modern design concept of inheritance of ethnic culture in Yunnan, with extraordinary significance development of the national clothing.

Firstly, by introducing Yunnan Miao, Yi, Dai ethnic culture, a better understanding of the characteristics of Yunnan minority costumes. Secondly, from the Yunnan national costume, color, pattern and process to detail their dress features. Once again, according to the characteristics of Yunnan ethnic costumes, ethnic costumes elements extraction, research and design about the different effects of the children's stage costume.
\end{abstract}

Keywords: National costumes, Children's stage costume, Miao, Yi, Dai

\section{Historical culture and fashion elements in Yunnan minority costumes}

\subsection{The overview of Ethnic costumes}

Costumes of ethnic minorities in Yunnan are deeply engraved on the historical culture. In the vicissitudes of history, political reform, economic development, the progress of science and technology, We can find its footprint.

And for most people, Miao Nationality is both familiar and unfamiliar, familiar with because there are a lot of introductions about it in all kinds of books, and unfamiliar because in real life, most people don't really come into contact, the mystery of it make people curious about it. Miao is a constant expelled nation, pleated skirt pattern and the square embroidery on the back, hidden the experience that they were in a far away from home and forced to constantly find new accommodation, but they never give up life. They built homes in the precipitous rock faces and sheer cliffs and built terraced fields on the hillside. They were with blood and tears to offspring, the worship of nature and thanks again for everything. This is a kind of spirit, a positive and optimistic, unyielding national spirit. (XIE Jialin, ZHU Hua, 2012)

Yi has very rich resources of ethnic culture. The clothing is colorful and the culture and art has a long history. The books about Yi recorded in various fields have a very high value for collection. Yi People's versatile, all kinds of traditional folk tunes are beyond count. Yi is a very rich culture resources of nation.

Dai is a beautiful and rich ethnic, its costumes are unique that can show off their slender, give a person a kind of beautiful, chic and elegant feeling. They have the rich aesthetic art. The Dai people firmly believe that: a woman's skirt and silver belt is the old ancestors left their treasures. (YU Xue, LI Peng, 2012)

The three ethnic groups have their own characteristics and rich culture connotation. They have very strong representative.

\subsection{Characteristics of the ethnic costumes}

Traditional ethnic costumes of Yunnan folk art are forms of life. It is a true portrayal of the life of the people and the emotion, so it has a unique personality. 


\subsubsection{The characteristics of the Miao costumes}

Miao dress has a long history. It is the collective consciousness of the Miao. From clothing strong ethnic characteristics shape, bright colors and exquisite embroidery pattern, can appreciate the colorful Miao costumes.

A. Miao costumes and colors

Miao costumes are unique, Miao women often wear Duijin linen jacket or Dajin wear linen embroidery, batik pleated skirt. Dress can be long or short, a plurality of lace ribbon corset, beautiful and moving. Color is one of the most beautiful Miao symbols, colorful patterns, pleated skirts have embroidery and cross stitch decorative. The color but also with gold rimmed increases the color gorgeous feeling. Miao costumes are in red, yellow, blue, black and white. (Fig 1-1)

\section{B. Miao dress Totem}

If the shape and color of clothing is the beauty of form, so the pattern is the beauty of content. A culture can be demonstrated by the totem pattern. The perfect combination of fashion modeling and totem pattern is to show the history and culture of the Miao costumes. Miao dragon image is embroidered in the image of their clothes and apron to express the totem of faith. Miao dress totem patterns are naive and full of infinite imagination and mysterious charm, we can get a glimpse of the rich from the totem patterns in this ancient national history and culture (Fig 1-2).

C. Miao clothing craft

Dress of the Miao people kept the traditional weaving techniques, embroidery and batik, embroidery, when used in one process, other techniques such as cross stitch them interspersed with embroidery, batik embroidery embroidery use, woven together, the colorfulflowers, dress patterns, highlighting the national art features (Fig 1-3).

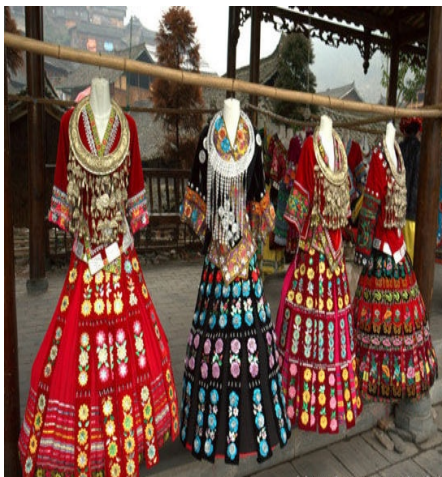

Figure 1-1 Miao clothing model and color

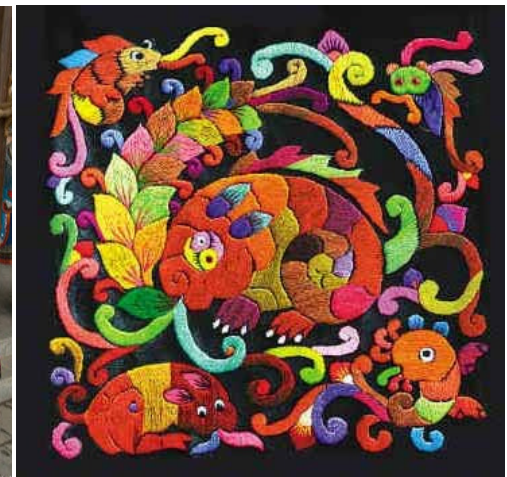

Figure 1-2 Miao dress pattern

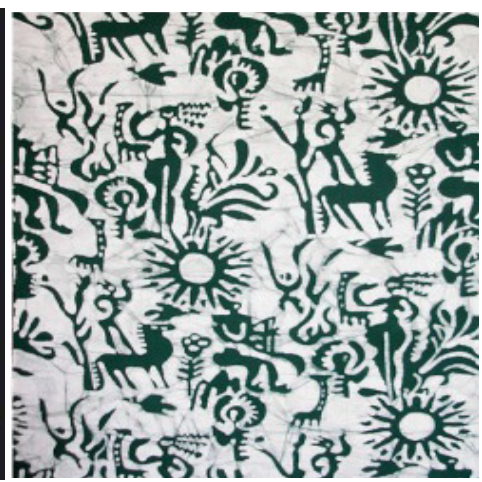

Figure 1-3 Miao batik process

\subsubsection{The characteristics of the Yi costumes}

Yi dress is a symbol of Yi culture, not only reflects the geographical features, but also embodies the traditional religion, history and culture, customs and ideas of Yi formed thousands of years. To retain their ethnic culture, Yi people created colorful costumes, formed its own unique system of the national dress culture. (LIU Haiqing, 2011)

A. Yi costumes and colors

Although Yi is set two settlements, but men's clothing is basically the same, for the collar and a pleated Duijin jacket. Yi women's dress is gorgeous, usually wearing embroidered Dajin coat, jacket embroidered vest, wearing a multi colored cloth dress, harmonious tone and elegant, unique style. Yi women like cockscomb shaped embroidered hat, worn on the head like a mighty big cock, beautiful and generous.

Yi dress with strength, hot and cold, rigid and strong color sense of shock, to convey the pure and holy, enthusiasm is bold and unrestrained, noble and mysterious, beautiful gorgeous traditional moral to the people of the world. The Yi ethnic cloths are mostly used bright colors, with color stitching highlights the distinctive color contrast effect. Yunnan Yi women like dark blue, green, red and blue, children's clothing are colorful and various patterns. The use of a variety of strong contrast color is full of children's naive and lively (Fig 1-4).

\section{B. Yi dress Totem}

$\mathrm{Yi}$ is a nation that has strong national colors and the flavor of life. Yi is the worship of dragon and tiger, so the dragon and tiger totem becomes an important aspect of $\mathrm{Yi}$ dress art in the overall design of clothing. The pattern designs 
include the sun and the moon, mountains and rivers, the rainbow, leaves, flowers and other natural scene. These patterns are in different poses and with different expressions, simple and pure, reproduction of the Yi ethnic style, the expression of the Yi People's yearning for a better life (Fig 1-5).

\section{Yi clothing craft}

Yi embroidery is not affected by latitude and longitude limitations, combined with the pick, pressure, embedded technology, three-dimensional sense of strong, suitable for embroidered flower patterns. so Yi, embroidery is one of the most representative process, is often used to coat, skirt, trousers, wallet etc. (Fig 1-6)

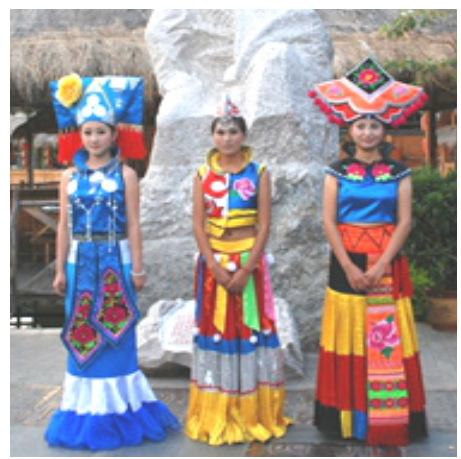

Figure 1-4 Yi clothing model and color

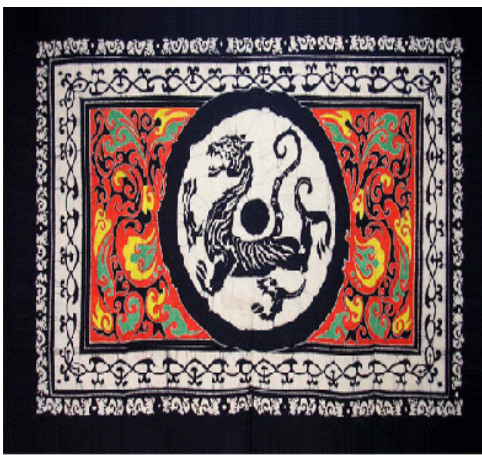

Figure 1-5 Yi dress pattern

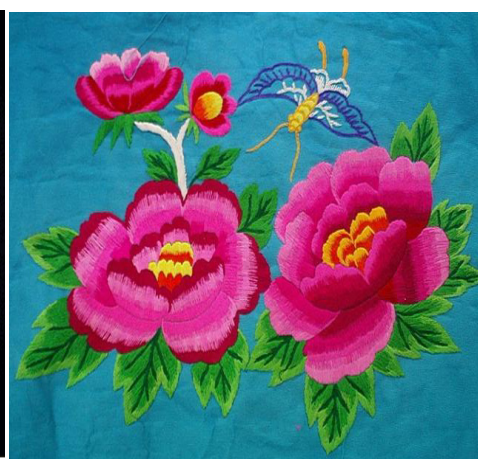

Figure 1-6 Yi embroidery

\subsubsection{The characteristics of the Dai costumes}

Located in the beautiful south, Yunnan Dai dress is gentle and beautiful, the most representative is the tight skirt. Colorful tight skirt can best embody the Dai People's aesthetic ideas and national feelings, different regions of the Dai dress are also different.

\section{A. Dai costumes and colors}

Dai nationality live in the Xi shuang ban na area, was affectionately known as "water dai". In the area of women like lighter color, they often wear a long tight skirt of bright colours, and then sets out a double breasted jacket or collar short jacket .Settled in Yuanjiang area "Huayao Dai", women's preference is full of silver vest, in the collar cuffs inlaid color embroidery lace or chest hung a variety of silver. A plurality of uneven tight skirt is covered with colorful embroidery lace. The Dai people in Dehong region is often called "HanDai", the women often wear a lighter color, black or cloth, clothes with short length and narrow sleeves, waist line a fine embroidered aprons, wide skirt. (YUAN Aili, 2011) (Fig 1-7)

\section{B. Dai dress Totem}

There are all kinds of animals and plants totem patterns and geometric patterns. The Dai people skillfully put peacock feather pattern in clothing accessories, vivid, expressed their good and happiness life. Each pattern has a specific meaning, such as the peacock--luck and happiness, the elephant--cereal harvest (Fig 1-8).

\section{Dai clothing craft}

Dai brocade technique create beautiful Dai dress. Brocade is to use a different color of the warp and weft interwoven into a variety of patterns and styles throughout the cotton or silk fabric. Its greatest feature is the use of two or more different colors lines of longitude and latitude according to the order of the formation of the satin weave woven. The brocade patterns are symmetry, and well-proportioned (Fig 1-9). 


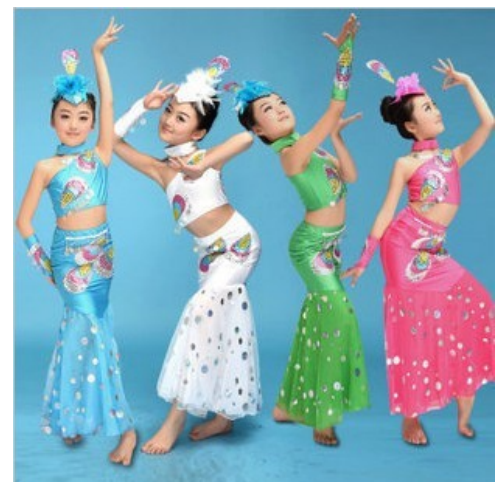

Figure 1-7 Dai clothing model and color

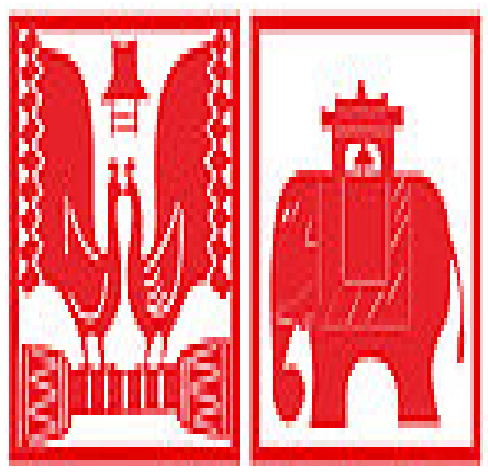

Figure 1-8 Dai dress pattern

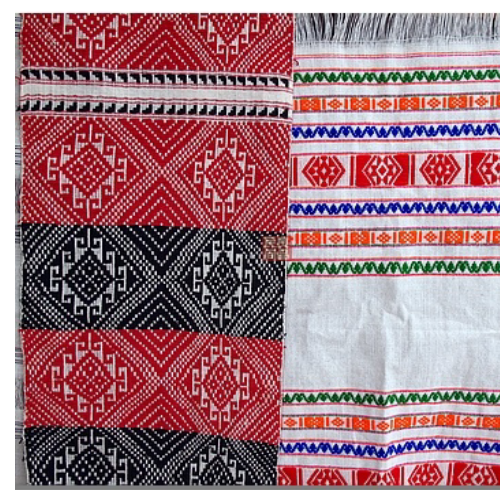

Figure 1-9 Dai brocade

\section{Application of Yunnan national costume elements in children in stage costume}

\subsection{The characteristics of children's stage}

Children's stage clothing style, color and fabric and other elements constitute the overall style of children's stage clothing, through the visual image of the external beauty of clothing into the inner spirit of clothing. Among them, the national style of clothing has a rustic simplicity and rich cultural flavor, is represented by the strong contrast color combinations of traditional decorative patterns and craft.

Children's stage clothes focus on the effect of stage performance, requiring rich colors, comfortable fabrics, patterns and diverse, unique, lively and full performance innocent child's personality, enhanced characters artistic appeal. Stage costumes are mainly two forms. A prominent fashion sense, the performance of on-site visual impact; another manifestation of the diversity of national costumes, traditional national costume for the prototype, with a stylish redesign, outstanding personality among national costumes and exaggerated. (QI Ji, 2013)

Through stage performances of modern children, the stage of fashion charm with a strong national integration, Children can perform in pure individuality while inheriting the national culture and carrying forward the national spirit.

\subsection{Design principles and methods}

In the design stage clothes for children, the conversion of National Costume image elements includes the overall grasp extraction methods and details. The former is the national dress of Yunnan from the overall style, the extension method can highlight the Yunnan minority costumes "spirit"; the extraction rule refers to the details of the design characteristics of Yunnan ethnic costumes and emphasizes the design concept of "shape".

In the fashion design process, we can learn from the national clothing style, color, pattern, technology and other factors, in order to grasp the overall style of the national characteristics, shear and vertical style structure with plate making clothing.

\subsection{Folk style design of children's stage}

Nowadays, national wind is popular in the world. In order to better the charm of Chinese Yunnan national simple inheritance, the national power generation, borrow the glittering stage, make full use of the performance form of national culture in the silent language, ethnic costumes, is inheriting the national culture, carry forward the national spirit in the best way.

\subsubsection{The first design}

\section{A. The impression drawing}

According to the style of stage performance and ethnic characteristics, coat bottom with a circle of sesame, pendant, fully show the characteristics of children's lively, accompanied by three cross stitch patterns on the waist, waist cloth with green represents the innocence of children and minorities in Yunnan worship of nature (Fig2-1). 


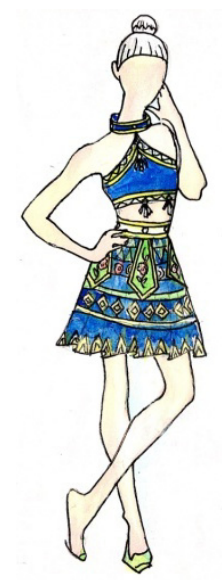

Figure 2-1 the first impression drawing

B. The design results

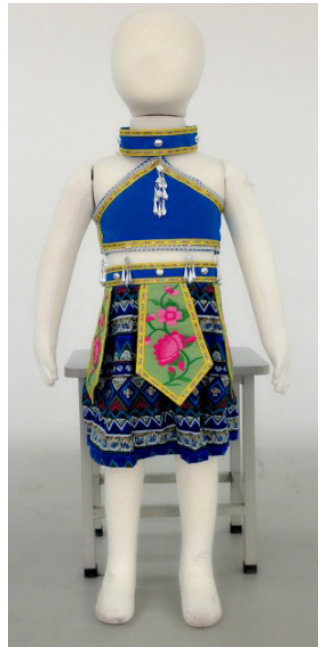

The front

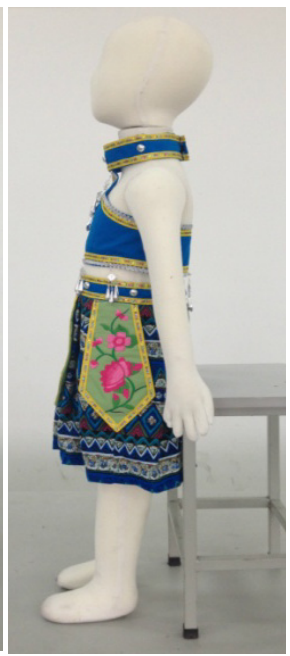

The side

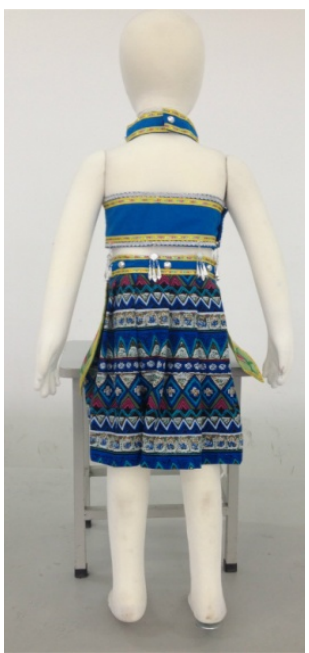

The back

Figure 2-2 the first finished drawing

Button design top side seam convenient children wearing batik fabric made of pleated skirt and lace embroidery embodies the strong national flavor, sesame bell pendant decoration show the vivid effect of children's stage performance in the expression of national culture (Fig 2-2).

\subsubsection{The second design}

\section{A. The impression drawing}

The style design with small collar, jacket, skirt symmetric absorption characteristics of Yi colored cloth, with silver, lace corset decoration, the national element thick applied to modern children's costumes, inheriting the national culture, carry forward the national spirit, but also to show children's stage performance. Asymmetric and symmetric comparative jacket skirt, the full performance of the children lively and cheerful, active thinking character; combining batik fabric and cotton fabric to ensure that children wear comfort in the performance of national charm (Fig2-3). 


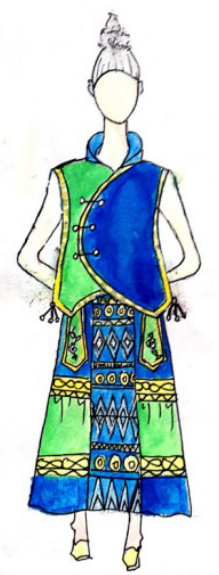

Fig 2-3 the second impression drawing

B. The design results

Cross stitch embroidery lace bodice and decoration of ethnic flavor is very strong, the skirt piece mosaic with different color cloth, with lace embroidery and silver gown, cake skirt, the inheritance of national culture but also reflects the nature of the child lively and lovely (Fig2-4).

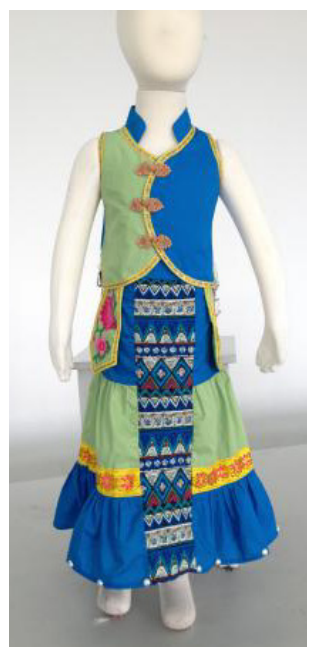

The front

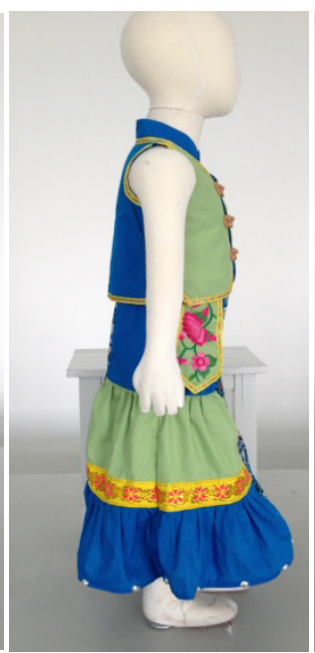

The side

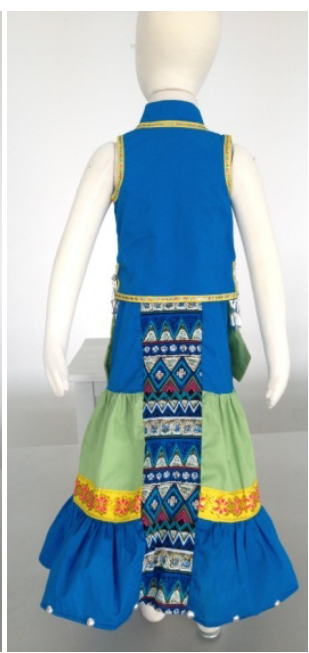

The back

Figure 2-4 the second finished drawing

2.3.3 The third design

A. The impression drawing

The inspiration comes performance characteristics

from Dai dress, asymmetric's coat, colorful skirt, with lace decoration, full (Fig2-5). 


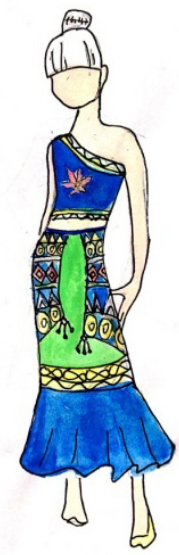

B. The design results

Figure 2-5 the third impression drawing

It is consistent with the effect chart. Decoration and batik fabrics made by the asymmetric form, reflect the contemporary national fashion sense, a tether belt type, convenient children dressed in national costumes, but also it can reflect the plain. (Fig 2-6)

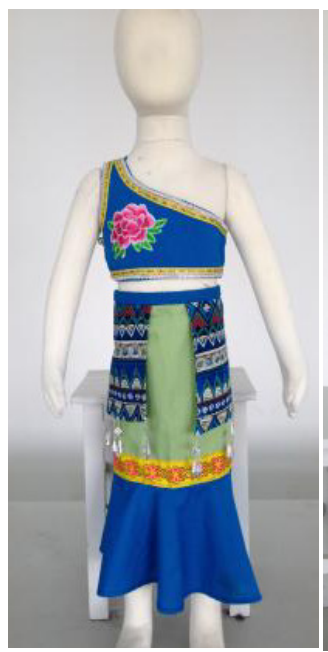

The front

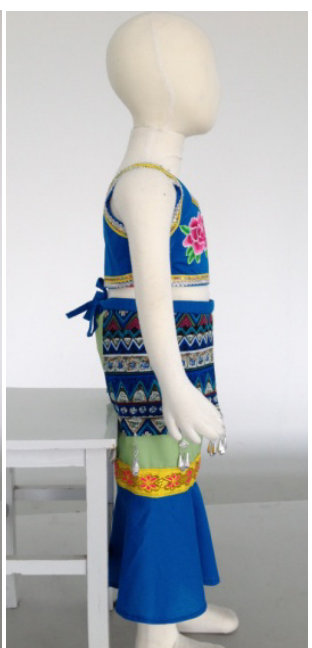

The side

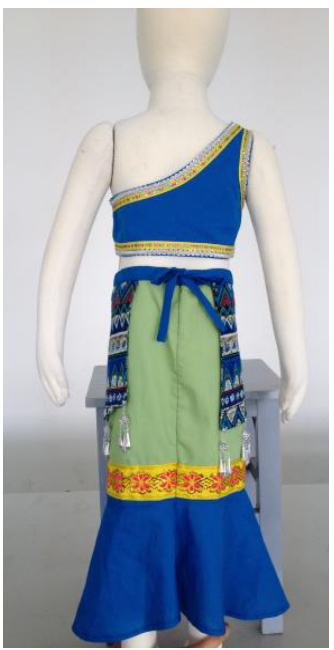

The back

\section{Summary and prospect}

Figure 2-6 the third finished drawing

This paper is based on the research and experience of Yunnan minority costume elements in children's clothing in the stage. After practice, I can sum up the following conclusions:

A. In the design of children's clothing stage, traditional costumes are the need for bold innovation into more fashionable and individual elements. In the style of a design in modern fashion design, will go into the design of costumes dance of the service station, add sesame Lin pendants and silver bubble decoration, as well as the stage effect and reflects the ethnic flavor.

B. Color is an important part of stage costume design, understanding of the various ethnic preferences for color, bold use of bright colors to decorate the elements, and the corresponding material combination, to show the children lively, innocent personality. In the design of the second, the multi colored cloth stitching, cake skirt like. Embroidered apron at the bottom of the green, to convey the Yunnan minority love for nature and worship.

C. The choice of fabric is on the basis of the national tradition in Yunnan and on the children's tender skin, three clothing of choice or cotton, breathable fabric, batik fabrics with comfortable, let the children display national culture on the stage of natural performance. 
D. In the totem of choice, the characteristics of various ethnic totem worship, geometric patterns and styles of the two styles, three styles of corset lace embroidery and batik fabric coat patterns on all draw national costume elements. Choosing the flowers and plants to decorate and make more ethnic costumes.

With the rapid development of economy, science and technology, the national culture has been to the world. It has a great influence on the development of national culture of fashion design. Designing of children's stage dress can show the children lively expressive force on the stage and the inheritance of national culture. Studied in Yunnan national dress style, the fabric, color, craft, and the design of its application to children in the stage is very good now. It needs further investigation about making national costume elements into modern fashion concept, to further improve the design of the modern ethnic costumes dance of the service station, more clearly inheriting the national spirit in the following fashion. At the same time, this requires us to constantly in-depth study to explore and create a new way to design our national dress and struggling.

\section{Acknowledgement}

This project is sponsored by Shanghai University of Engineering Science 2015-year Innovation Fund for Graduate Students.

\section{References}

LIU Haiqing. (2011). To explore the types and patterns of traditional costumes of Yunnan Honghe region of the Yi Nationality. Journal of Nanning College for Vocational Technology, 2011, 16:16-19.

QI Ji. (2013). The innovation of Ethnic elements and fashion design. Study of literature and art, 2013, (11):157-158.

XIE Jialin, ZHU Hua. (2012). The significance of applying Miao embroidery to modern children's clothing design. Modern Decoration: Theory, 2012,(2).

YU Xue, LI Peng. (2012). The application of Dai dress element in modern clothing design. Intelligence, 2012,(2).

YUAN Aili. (2011). To explore the aesthetic value of Yunnan minority costumes -- a case study of Dai dress. Cultural and educational information, 2011, (18):75-76. 